\title{
Final Thoughts
}

Michael R. Hamrell, PhD

Correspondence Address

Michael R. Hamrell

(email:Michael@

moriahconsultants.com).
After 6 years as the editor in chief of the Drug Information Journal, it is time for me to turn the responsibilities over to a new editor.

As an active DIA member for more than 25 years, I have personally witnessed our association's tremendous growth and change. During my tenure as your editor in chief, I have worked very diligently to support and further the mission of the founding members of DIA and the journal. Their goal was to provide a quality scholarly publication to disseminate information on clinical research and drug development issues to the membership of DIA. During the last 6 years, you have seen changes in the format and layout of the journal. I advocated and the DIA board of directors supported expanding the journal's publication schedule from quarterly to 6 times per year. This was implemented in 2007 to increase the availability of articles for drug information professionals and provide more timely access to the journal's content. I expanded the editorial board and guest editors, the individuals who give freely of their time to provide the excellent scholarly reviews of the submitted manuscripts and whose efforts have helped in my determinations about which articles should be published. I am eternally indebted to all of you for your time, effort, and support over the past 6 years.

More importantly, my job and the work as the editor and with the editorial board would not have been possible without tremendous support from all the DIA staff members who work on the journal. To all of the staff who helped, supported, and contributed to the journal over the years, I thank you. I could never have accomplished my job without your help. I also offer my thanks to Tom Teal, the founder and first editor of the journal and now editor emeritus. for his sage advice and counsel over the years.

As a past member of the journal's editorial board, I've had the pleasure of serving with the journal's two past editors. As only the third editor in chief of the journal, it has been a tremendous honor and privilege to have served in this position for these past 6 years. I offer my best wishes and support to the new editor in chief. and I know all of you will welcome and support him in taking the journal forward to the next level. 